\title{
A strategic plan for scientific drilling in the East African rift lakes
}

\section{Providence, USA, 14-16 November 2011}

James M. Russelli , A.S. Cohen ${ }^{2}$, T.C. Johnson ${ }^{3}$ AND C.A. SCHOlZ ${ }^{4}$

'Department of Geological Sciences, Brown University, Providence, USA; James_Russell@Brown.edu

${ }^{2}$ Department of Geosciences, University of Arizona, Tucson, USA; ${ }^{2}$ Large Lakes Observatory, University of Minnesota Duluth, USA; ${ }^{4}$ Department of Earth Sciences, Syracuse University, USA

T: he East African Rift Lakes offer unparalleled opportunities to investigate long-term environmental and climatic change in a low-latitude continental setting. Their sediments hold signals of the evolution of tropical temperature and rainfall at seasonal to geological timescales (Cohen et al. 2006; Tierney et al. 2008), record the environmental backdrop against which Africa's flora and fauna - including our own species - evolved (Martens 1997), and provide insight into tectonic processes that shape the world's largest active continental rift system (Ebinger 1989). The past decade has witnessed enormous advances in our efforts to obtain long records of East African climate, highlighted by the scientific drilling of Lake Malawi in 2005 (Scholz et al. 2007). Recent and ongoing geophysical surveys of a number of potential future drilling targets, including Lakes Turkana, Albert, and Tanganyika (Fig. 1), have set the stage for the next phase of continental scientific drilling in East Africa. To this end, PAGES and the US National Science Foundation supported a "Continental Drilling in the East African Rift Lakes" strategic planning workshop, attended by about 40 African, European, and US scientists.

We used plenary presentations on current initiatives to reconstruct and model East African paleoenvironments using marine and lacustrine sediments, the mechanisms behind the geologic and biological evolution of the East African rift, and the stratigraphic architecture and environmental history of Lakes Turkana, Albert, and Tanganyika to initiate a series of breakout discussions. These breakouts defined critical scientific hypotheses and questions for future drilling projects, including:

- What are the timing and dynamics of key transitions in the Plio-Pleistocene evolution of African climate as a consequence of global and tropical climate reorganizations, including the expansion of Northern Hemisphere ice sheets, the termination of a permanent Pliocene El Niño, and the closure of the Indonesian seaway?

- What is the sensitivity of East African temperature and rainfall to radiative forcing (insolation and greenhouse gases) and high-latitude processes?

- What are the rates and amplitudes of millennial to decadal East African climate change, and how do these vary with changes in the Earth's mean climate state?

- What are the rates, sensitivities, and thresholds for ecological and evolutionary responses of ecosystems and communities to climate and environmental change across different timescales?

- What are the regulating mechanisms and emergent properties of the dissociation and reassembly of aquatic

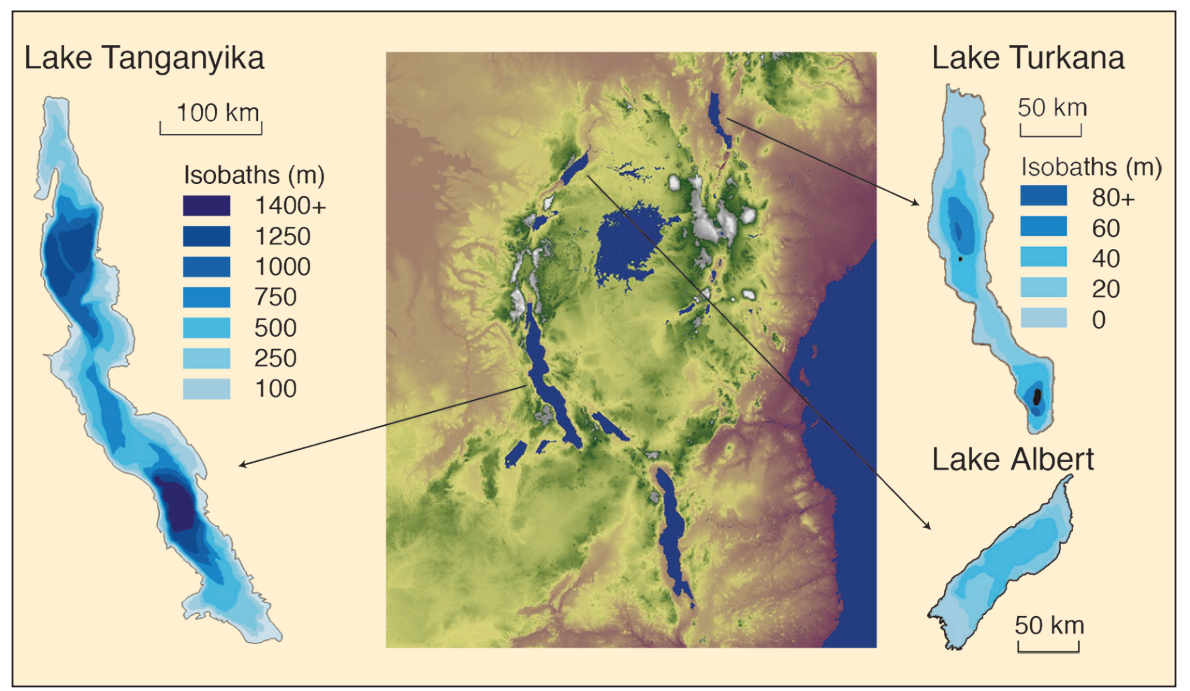

Figure 1: Map of East Africa with bathymetric maps of Lakes Tanganyika, Turkana, and Albert. Note the different scale for Tanganyika. ecosystems and communities through time?

- What are the rates of border fault slip in the rift basins, how are they controlled by geothermal gradients and volatile concentrations, and how do long-term fault slip rates relate to shortterm seismic hazards such as earthquake frequency?

Addressing these questions will require analysis of long and continuous sediment cores that archive signals of climate variability at a hierarchy of timescales (seasonal, interannual, orbital); sites that preserve a variety of biological materials such as pollen, diatoms, ostracods, and fish remains; and integrated, 4-D studies of rift evolution.

While Albert, Turkana, and Tanganyika can all provide insight into the climatic, biological, and geological evolution of East Africa, the group nominated Lake Tanganyika as its highest priority target. Tanganyika uniquely holds long and continuous sedimentary records extending well into the Pliocene at modest $(1-1.5 \mathrm{~km})$ drilling depths (McGlue et al. 2008), an extraordinary variety of endemic lacustrine fauna and flora with proven fossil records, and a relatively simple rift architecture uncomplicated by extensive volcanism. Efforts are now underway to acquire new intermediate resolution seismic reflection data from Tanganyika to site drilling targets, reanalyze existing Tanganyika sediment cores to expand our arsenal of proxies, and to build our knowledge of the structural evolution and tephra stratigraphy of this basin. These activities will refine our understanding of the environmental evolution of tropical East Africa, and serve as milestones in the road to drilling Lake Tanganyika.

\section{References}

Cohen AS et al. (2006) Journal of Paleolimnology 36(2): 189-209 Ebinger CJ (1989) Geological Society of America Bulletin 101: 117-133 Martens K (1997) Trends in Ecology and Evolution 12: 177-182 McGlue MM et al. (2008) Journal of Paleolimnology 40: 635-653 Tierney JE et al. (2008) Science 322: 252-255 